\title{
DISPOSIÇÃO DE LODO DE ETE DE INDÚSTRIA ALIMENTÍCIA NO SOLO: EFEITOS NA ÁGUA SUBTERRÂNEA
}

\author{
DISPOSAL OF SLUDGE FROM FOOD INDUSTRY WASTEWATER TREATMENT \\ PLANT ON SOIL: EFFECTS ON GROUNDWATER
}

\author{
Ana Carolina Amaral PEREIRA ${ }^{1}$ \& Marcelo Loureiro GARCIA ${ }^{2}$ \\ (1) Programa de Pós-Graduação em Geociências e Meio Ambiente, Instituto de Geociências e Ciências Exatas. \\ Universidade Estadual Paulista - UNESP. Avenida 24-A, 1515 - Bela Vista, CEP: 13.506-900, Rio Claro, SP. \\ Endereço eletrônico: w.anapereira@gmail.com \\ (2) Departamento de Petrologia e Metalogenia, Instituto de Geociências e Ciências Exatas \\ Universidade Estadual Paulista - UNESP. Av. 24A, 1515, Bela Vista, CEP 13506-900. Rio Claro, SP \\ Endereço eletrônico: mlgarcia@ rc.unesp.br
}

\author{
Introdução \\ Metodologia \\ Resultados e Discussão \\ Conclusões \\ Referências Bibliográficas
}

\begin{abstract}
RESUMO - O lodo proveniente de estações de tratamento de efluentes é rico em nutrientes e possui alto teor de matéria orgânica, podendo desempenhar importante papel no condicionamento do solo e na produção agrícola. Entretanto, é importante que sua utilização no solo seja feita de maneira controlada devido à possibilidade da presença de substâncias poluentes e contaminantes. O presente trabalho objetivou analisar os efeitos da aplicação em escala real de lodo de estação de tratamento de efluentes em uma área de latossolo cultivado com eucalipto (Eucalyptus sp.) na água subterrânea. Os resultados indicam concentrações maiores de bário e zinco na água subterrânea sob influência da aplicação de lodo em relação ao poço testemunha, mas não está claro se a diferença observada está relacionada à disposição do resíduo no solo. Não foram verificadas alterações quanto às substâncias orgânicas potencialmente tóxicas e aos indicadores microbiológicos. Todos os parâmetros analisados na água subterrânea atendem ao padrão de qualidade determinado na Resolução CONAMA no420/2009 e ao padrão de potabilidade definido na Portaria MS no 2914/2011.

Palavras-chave: Disposição de Lodo no Solo; Lodo de ETE; Água Subterrânea

ABSTRACT - Sludge from wastewater treatment plants usually contains high levels of organic matter and nutrients, and therefore it can be used as fertilizer and soil conditioner. However, its disposal on the soil has to be properly managed because it can contain contaminants. The aim of this work was to investigate the effects of soil disposal of food industry sludge on the groundwater. The results show a higher concentration of barium and zinc in the groundwater under the influence of the sludge disposal in comparison with the control area, but it is not clear whether this difference is due to the sludge application on the soil. It was not observed scenario change for toxic organic substances and microbiological indicators. All groundwater parameters met the water quality standards set by Brazilian Federal Regulations (Resolução CONAMA nº 420/2009 and Portaria MS no 2914/2011).
\end{abstract}

Keywords: Sludge Disposal on Soil; Wastewater Sludge; Groundwater.

\section{INTRODUÇÃO}

Uma das principais fontes de poluição dos rios no Brasil é o despejo de efluentes industriais e domésticos sem o tratamento prévio adequado. As estações de tratamento de efluentes (ETEs) têm como objetivo a remoção dos poluentes, nutrientes e matéria orgânica presentes nas águas residuárias antes que retornem ao meio ambiente por meio de despejo nos corpos d'água. Além do efluente tratado, as ETEs geram como subproduto um resíduo de natureza predominantemente orgânica denominado lodo. O lodo produzido em uma ETE corresponde a cerca de 1 a $2 \%$ do volume do efluente tratado, entretanto o tratamento e a disposição final deste resíduo representam de 30 a $50 \%$ do custo operacional da estação
(Sanepar, 1999). Para que um sistema de tratamento alcance plenamente seus objetivos, além de sua correta operação em termos de eficiência de remoção de poluentes e de carga orgânica, é fundamental que o lodo gerado seja corretamente disposto.

Uma alternativa de manejo do lodo é a aplicação no solo. O lodo biológico é rico em nutrientes e possui alto teor de matéria orgânica, por isso sua aplicação como condicionador pode aumentar a qualidade física e química do solo. As características do lodo gerado em ETEs são muito variáveis, pois dependem diretamente origem do efluente bruto e do tipo do tratamento a que é submetido. O lodo de esgoto sanitário tende a ter alta 
concentração de patógenos (Silva et al., 2001) e pode apresentar também contaminantes químicos (Saito, 2007; Smith, 2009). Por outro lado, as características de lodos de ETEs industriais dependem do tipo de processo produtivo e insumos utilizados, sendo também fontes potenciais de contaminação.

Em alguns países, a aplicação de lodo no solo ocorre há mais de vinte anos em escala operacional com a destinação de grande parte do lodo gerado para plantações florestais (Lira et al., 2008) e esta prática é mais recente no Brasil (Saito, 2007). Existem vários trabalhos na literatura que avaliaram, sob condições específicas e diferentes, os impactos ambientais positivos e negativos derivados da disposição do lodo no solo. Os impactos positivos da disposição de resíduos no solo referem-se ao aumento da produtividade da cultura (Lira et al., 2008; Silva et al., 2008; Mingorance et al., 2014; Nascimento et al., 2004; Méndez-Contreras et al., 2009; Paiva et al., 2009; Fuess \& Garcia, 2014), o aumento da capacidade de troca cationica e da disponibilidade de nutrientes (Unal \& Katkat, 2009; Asik et al., 2015 Mingorance et al., 2014; Nascimento et al., 2004; Fuess \& Garcia, 2014), o aumento do poder de retenção de água do solo e a elevação do $\mathrm{pH}$ (Brito et al., 2013; Fuess \& Garcia, 2014), a melhora da estrutura física do solo e o aumento e da atividade microbiana (Mingorance et al., 2014; Fuess \& Garcia, 2014), enquanto a salinização dos solos (Fuess \& Garcia, 2014), a contaminação de águas subterrâneas (Dynia et al., 2006; Harrison et al., 1994; Fuess \& Garcia, 2014) e o acúmulo de metais no solo (Silva et al., 2001; Asik et al., 2015; Silva et al., 2006) e na cultura (Silva et al., 2006) são enumerados como os principais impactos negativos.

Dessa forma, o objetivo deste trabalho foi avaliar os efeitos da disposição, em escala real, de lodo de ETE de uma indústria do ramo alimentício no solo, sobretudo os impactos ambientais causados na água subterrânea.

\section{METODOLOGIA.}

O estudo de caso foi baseado no monitoramento técnico-ambiental da aplicação de lodo realizada durante cinco semestres por uma indústria do ramo alimentício de transformação de produtos agrícolas (frutas e legumes). A indústria era responsável pela disposição de lodo no solo e gentilmente cedeu os dados operacionais e os resultados laboratoriais do monitoramento realizado nos semestres 3, 4 e 5 .

O lodo foi gerado na estação de tratamento de efluentes (ETE) da indústria, localizada na região metropolitana de Goiânia/GO. A ETE é constituída de tratamento primário (peneira rotativa, coagulação [sulfato de alumínio] e flotação) e secundário (lodos ativados) e apresenta vazão média mensal de $3.607 \mathrm{~m}^{3}$, sendo constituída amplamente por efluentes industriais, proveniente do processo produtivo, e por esgoto sanitário (contribuição de 3 a $4 \%$ ou de 108 a $144 \mathrm{~m}^{3} / \mathrm{mês}$ ). O lodo que foi aplicado no solo era uma mistura de lodo primário e lodo secundário, e a quantidade média gerada por mês pela ETE é de 437,5 toneladas, em base seca. Antes da aplicação no solo, o lodo foi desaguado em centrífuga até atingir umidade aproximada de $70 \%$, e recebeu a adição de cal em quantidade suficiente para elevação do $\mathrm{pH}$ do resíduo a 12 nos semestres 3 e 4. O lodo não sofreu processo de caleação no semestre 5. O lodo foi aplicado superficialmente no solo nas entrelinhas dos eucaliptos e posteriormente incorporado ao solo.

A área de disposição de lodo consiste em uma fazenda de plantio comercial de eucalipto (Figura 1). A área agrícola onde foi realizado o trabalho é constituída por um latossolo vermelho de textura argilosa, na região metropolitana de Goiânia (Souza, 2010). Foram utilizadas cinco glebas de cultura de eucalipto que totalizam 53,2 hectares. As glebas 1, 2, 3 e 4, com 39,9 hectares no total, foram utilizadas durante dois anos e meio para aplicação do lodo e uma área de 13,3 hectares, denominada gleba testemunha, manteve-se sem aplicação. A aplicação ocorreu em um período total de cinco semestres. A taxa de aplicação em base seca por gleba e por período é apresentada na Tabela 1 . 


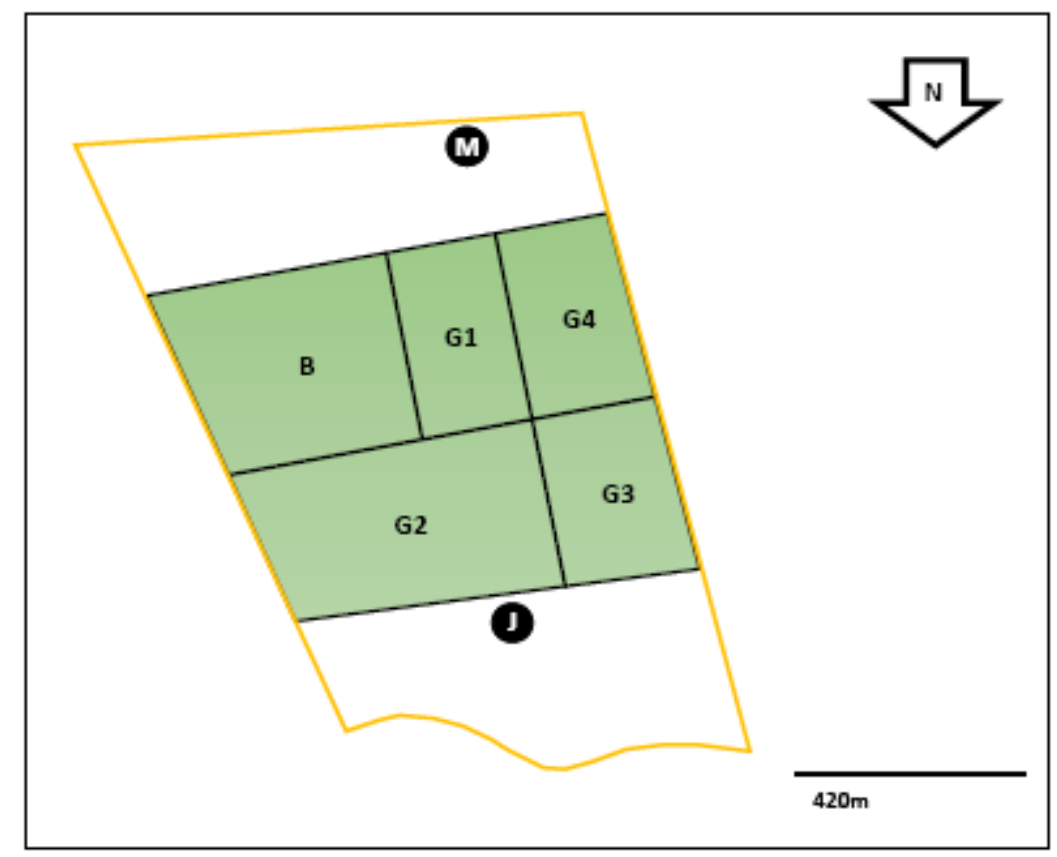

Figura 1 - Área de aplicação do lodo. Legenda: G1, G2, G3 e G4 = glebas 1, 2, 3 e 4, respectivamente; B = gleba testemunha; $\mathrm{M}=$ poço de monitoramento montante; $\mathrm{J}=$ poço de monitoramento jusante; linha amarela = perímetro da propriedade.

Tabela 1 - Taxa de aplicação em base seca $\left(\right.$ t.ha $\left.^{-1}\right)$ por gleba.

\begin{tabular}{c|c|c|c|c}
\hline Gleba & Área (ha) & Período de aplicação & Quantidade aplicada (t) & Taxa de aplicação (t.ha-1 \\
\hline Gleba 1 & 7,4 & Semestre 3 e 4 & 638,0 & 86,2 \\
\hline \multirow{2}{*}{ Gleba 2 } & \multirow{2}{*}{16,6} & Semestre 1 e 2 & 2449,4 & 147,5 \\
\cline { 3 - 5 } & & Semestre 5 & 439,2 & 26,5 \\
\hline Gleba 3 & 8,5 & Semestre 1 e 2 & 1254,2 & 147,5 \\
\hline Gleba 4 & 7,4 & Semestre 1 e 2 & 1091,9 & 147,5 \\
\hline
\end{tabular}

Uma amostra simples de lodo foi coletada, na centrífuga de desaguamento do lodo da estação de tratamento de efluentes, dos lotes de lodo correspondentes aos semestres 3, 4 e 5. As análises foram realizadas pelo laboratório Bioagri Ambiental LTDA, Uberlândia/MG. Foram analisados os parâmetros de macro e micronutrientes, constituintes inorgânicos e substâncias orgânicas potencialmente tóxicas (Pereira \& Garcia, 2017) e os parâmetros microbiológicos coliformes, ovos viáveis de helmintos e salmonela, conforme descrito por USEPA (2003), e foram realizados testes de hipótese $\mathrm{t}$ de Student, considerando o nível de confiança de 95\%, utilizando-se para tal o software BioEstat 5.3, para a verificação da significância da diferença estatística dos resultados laboratoriais.

$\mathrm{Na}$ área de estudo existem dois poços de monitoramento de águas subterrâneas, que foram instalados com tubo geomecânico de PVC de 2,0 polegadas, sendo um a montante (PMM) e outro a jusante (PMJ) da área de aplicação de lodo. O poço a montante da área de aplicação tem a função de poço testemunha ou branco por não sofrer a influência da aplicação de lodo.

Com a utilização de amostradores descartáveis tipo bailer, os poços de monitoramento foram esgotados, ou seja, a água estagnada no poço e no pré-filtro foi removida para ser substituída por água de formação. É importante que este procedimento seja realizado antes da coleta das amostras para que a água coletada seja representativa da água subterrânea do local. Em até 24 horas após o esgotamento foi coletada uma amostra de água de cada um dos poços. As amostras de água subterrânea, relativas ao semestre 5, foram também analisadas pelo laboratório Bioagri Ambiental 
LTDA quanto aos parâmetros microbiológicos e constituintes inorgânicos de acordo com métodos descritos em Standard Methods for the Examination of Water and Wastewater (APHA; AWWA; WEF et al., 2012) e substâncias orgânicas potencialmente tóxicas pelos métodos 8270d (USEPA, 2007) e 8260c (USEPA, 1996). Não houve possibilidade de coleta de amostras de água subterrânea nos semestres 3 e 4 devido ao baixo nível da água nos poços.

\section{RESULTADOS E DISCUSSÃO}

Os resultados referentes aos indicadores microbiológicos e agentes patogênicos do lodo são apresentados na Tabela 2. Todos os parâmetros analisados indicam que o lodo está de acordo com a legislação vigente, a Resolução CONAMA no 375/06 (BRASIL, 2006), estando dentro dos limites referentes à classe A, com exceção do parâmetro coliformes termotolerantes nas análises dos semestres 3 e 5 . O lodo foi submetido a um processo de redução de patógenos por adição de cal nos semestres 3 e 4 . O parâmetro coliformes termotolerantes apresentou-se ligeiramente acima do limite máximo para sua classificação em classe A no semestre 3. O lodo não sofreu processo de caleação no semestre 5 e, por este motivo, apresentou índices elevados de coliformes termotolerantes.

Os resultados laboratoriais referentes aos indicadores bacteriológicos na água subterrânea seguem apresentados na Tabela 3.

Tabela 2 - Indicadores microbiológicos e agentes patogênicos do lodo.

\begin{tabular}{|c|c|c|c|c|c|c|}
\hline \multirow{2}{*}{ Parâmetro } & \multirow{2}{*}{ Unidade } & \multicolumn{3}{|c|}{ Resultados Analíticos } & \multicolumn{2}{|c|}{$\begin{array}{c}\text { Limite máximo da } \\
\text { Resolução CONAMA } \\
\text { n⿳0 } 375 / 06^{\circ}\end{array}$} \\
\hline & & Semestre 3 & Semestre 4 & Semestre 5 & $\begin{array}{c}\text { Lodo tipo } \\
\text { A }\end{array}$ & $\begin{array}{c}\text { Lodo tipo } \\
\text { B }\end{array}$ \\
\hline $\begin{array}{l}\text { Coliformes } \\
\text { Termotolerantes } \\
(\text { E. coli) }\end{array}$ & NMP/g de ST & 1400 & $<130$ & 13980000 & $<10^{3}$ & $<10^{6}$ \\
\hline Enterovírus & $\mathrm{UFP} / \mathrm{g}$ de $\mathrm{ST}$ & Ausente & nd & Ausente & $<0,25$ & Não há \\
\hline $\begin{array}{l}\text { Ovos Viáveis de } \\
\text { Helmintos }\end{array}$ & Ovos/g de ST & $<0,1$ & $<0,1$ & $<0,25$ & $<0,25$ & $<10$ \\
\hline Salmonella sp. & $\begin{array}{c}\text { P/A em } 10 \mathrm{~g} \text { de } \\
\text { MS }\end{array}$ & Ausente & Ausente & Ausente & Ausência & Não há \\
\hline
\end{tabular}

Nota: Os valores antecedidos pelo sinal de "menor que" $(<)$ indicam que a quantidade da substância não alcançou o limite de quantificação da amostra. nd: não determinado. Amostras de lodo coletadas na centrífuga da estação de tratamento de efluentes nos semestres 3, 4 e 5, representativas do lodo disposto em todas as glebas nos períodos correspondentes.

Tabela 3 - Indicadores bacteriológicos na água subterrânea.

\begin{tabular}{|c|c|c|c|c|}
\hline Parâmetro & Unidade & Poço montante & Poço jusante & $\begin{array}{c}\text { Portaria MS no } \\
2914 / 11 \\
\end{array}$ \\
\hline Coliformes Termotolerantes $(E$. & P/A $100 \mathrm{~mL}$ & Ausentes & Ausentes & Ausência \\
\hline Coliformes Totais & P/A $100 \mathrm{~mL}$ & Presentes & Ausentes & Ausência \\
\hline
\end{tabular}

Nota: Amostras da água subterrânea coletadas nos poços de monitoramento no semestre 5.

Foram detectados coliformes totais na amostra de água subterrânea coletada no poço de monitoramento a montante, o que indica que a água não se apresenta de acordo com o padrão de potabilidade da Portaria do Ministério da Saúde no 2914/2011 (Brasil, 2011).

Uma vez que o parâmetro em desacordo foi detectado apenas na amostra coletada no poço de monitoramento de montante, infere-se que esta alteração da qualidade da água subterrânea não foi causada pela aplicação de lodo. Esta alteração pode ter ocorrido devido à contaminação a montante da propriedade, ou na própria coleta da amostra.

Os resultados laboratoriais referentes aos pesticidas organoclorados e ésteres ftálicos na água subterrânea seguem apresentados na 
Tabela 4 e os resultados laboratoriais referentes aos fenóis, metanos clorados, etenos clorados, etanos clorados, benzenos clorados, hidrocarbonetos policíclicos aromáticos e hidrocarbonetos aromáticos voláteis na água subterrânea seguem apresentados na Tabela 5.

Tabela 4 - Substâncias orgânicas na água subterrânea: pesticidas organoclorados e ésteres ftálicos.

\begin{tabular}{|c|c|c|c|c|c|}
\hline \multirow[b]{2}{*}{ Parâmetro } & \multirow[b]{2}{*}{ Unidade } & \multirow[b]{2}{*}{ Poço montante } & \multirow[b]{2}{*}{ Poço jusante } & \multicolumn{2}{|c|}{ Limite máximo } \\
\hline & & & & $\begin{array}{c}\text { CONAMA n } \\
420 / 2009 \\
\end{array}$ & \begin{tabular}{|c|} 
Portaria MS no \\
$2914 / 2011$ \\
\end{tabular} \\
\hline Aldrin + Dieldrin & $\mu \mathrm{g} . \mathrm{L}^{-1}$ & $<0,003$ & $<0,003$ & 0,03 & 0,03 \\
\hline Endrin & $\mu \mathrm{g} . \mathrm{L}^{-1}$ & $<0,01$ & $<0,01$ & 0,6 & 0,6 \\
\hline HCH Beta & $\mu \mathrm{g} . \mathrm{L}^{-1}$ & $<0,005$ & $<0,005$ & 0,07 & --- \\
\hline Lindano (g-HCH) & $\mu \mathrm{g} . \mathrm{L}^{-1}$ & $<0,003$ & $<0,003$ & 2 & 2 \\
\hline DDT + DDD + DDE & $\mu \mathrm{g} . \mathrm{L}^{-1}$ & $<0,002$ & $<0,002$ & 2 & 1 \\
\hline PCBs (lista holandesa) & $\mu \mathrm{g} . \mathrm{L}^{-1}$ & $<0,001$ & $<0,001$ & 3,5 & --- \\
\hline Di (2-etilhexil) ftalato & $\mu \mathrm{g} . \mathrm{L}^{-1}$ & $<1$ & $<1$ & 8 & 8 \\
\hline Dibutilftalato & $\mu \mathrm{g} . \mathrm{L}^{-1}$ & $<1$ & $<1$ & Não há & --- \\
\hline Dimetil Ftalato & $\mu \mathrm{g} . \mathrm{L}^{-1}$ & $<1$ & $<1$ & 14 & --- \\
\hline 2,3,4,5-Tetraclorofenol & $\mu \mathrm{g} . \mathrm{L}^{-1}$ & $<0,01$ & $<0,01$ & 10,5 & --- \\
\hline 2,3,4,6-Tetraclorofenol & $\mu \mathrm{g} . \mathrm{L}^{-1}$ & $<0,01$ & $<0,01$ & 10,5 & --- \\
\hline 2,4,5-Triclorofenol & $\mu \mathrm{g} . \mathrm{L}^{-1}$ & $<1$ & $<1$ & 10,5 & --- \\
\hline 2,4,6-Triclorofenol & $\mu \mathrm{g} . \mathrm{L}^{-1}$ & $<1$ & $<1$ & 200 & 200 \\
\hline 2,4-Diclorofenol & $\mu \mathrm{g} . \mathrm{L}^{-1}$ & $<1$ & $<1$ & 10,5 & --- \\
\hline 2-Clorofenol & $\mu \mathrm{g} . \mathrm{L}^{-1}$ & $<1$ & $<1$ & 10,5 & --- \\
\hline 3,4-Diclorofenol & $\mu \mathrm{g} . \mathrm{L}^{-1}$ & $<0,01$ & $<0,01$ & 10,5 & --- \\
\hline Pentaclorofenol & $\mu \mathrm{g} . \mathrm{L}^{-1}$ & $<0,05$ & $<0,05$ & 9 & 9 \\
\hline Cresóis Totais & $\mu \mathrm{g} . \mathrm{L}^{-1}$ & $<0,3$ & $<0,3$ & 175 & --- \\
\hline Fenol & $\mu \mathrm{g} . \mathrm{L}^{-1}$ & $<0,1$ & 0,13 & 140 & --- \\
\hline Tetracloreto de Carbono & $\mu \mathrm{g} . \mathrm{L}^{-1}$ & $<1$ & $<1$ & 2 & 4 \\
\hline Clorofórmio & $\mu \mathrm{g} . \mathrm{L}^{-1}$ & $<1$ & $<1$ & 200 & --- \\
\hline Diclorometano & $\mu \mathrm{g} . \mathrm{L}^{-1}$ & $<1$ & $<1$ & 20 & 20 \\
\hline Cloreto de Vinila & $\mu \mathrm{g} . \mathrm{L}^{-1}$ & $<1$ & $<1$ & 5 & 2 \\
\hline 1,1-Dicloroeteno & $\mu \mathrm{g} . \mathrm{L}^{-1}$ & $<1$ & $<1$ & 30 & 30 \\
\hline 1,2-Dicloroeteno & $\mu \mathrm{g} . \mathrm{L}^{-1}$ & $<2$ & $<2$ & 50 & 50 \\
\hline Tetracloroeteno & $\mu \mathrm{g} . \mathrm{L}^{-1}$ & $<1$ & $<1$ & 40 & 40 \\
\hline Tricloroeteno & $\mu \mathrm{g} . \mathrm{L}^{-1}$ & $<1$ & $<1$ & 70 & 20 \\
\hline 1,1,1-Tricloroetano & $\mu \mathrm{g} . \mathrm{L}^{-1}$ & $<1$ & $<1$ & 280 & --- \\
\hline 1,1-Dicloroetano & $\mu \mathrm{g} . \mathrm{L}^{-1}$ & $<1$ & $<1$ & 280 & -- \\
\hline 1,2-Dicloroetano & $\mu \mathrm{g} . \mathrm{L}^{-1}$ & $<1$ & $<1$ & 10 & 10 \\
\hline
\end{tabular}

Nota: Os valores antecedidos pelo sinal de "menor que" $(<)$ indicam que a quantidade da substância não alcançou o limite de quantificação da amostra. --- Não se aplica. Amostras da água subterrânea coletadas nos poços de monitoramento no semestre 5 .

Todos os parâmetros analisados resultaram abaixo do limite de quantificação da amostra, e estão de acordo com o padrão de qualidade ambiental determinado na Resolução CONAMA n420/2009 (BRASIL, 2009), e com o padrão de potabilidade definido pela Portaria $M S n^{\circ}$ 2914/2011. A maioria dos parâmetros orgâni- cos analisados apresentou-se abaixo do limite de quantificação da amostra e não apresentou variação dos resultados entre as amostras de montante e de jusante. Os parâmetros fenantreno, fenol e naftaleno apresentaram resultado levemente acima dos limites de quantificação, respectivamente $0,08,0,13$ e $0,06 \mu \mathrm{g} . \mathrm{L}^{-1}$. 
Tabela 5 - Substâncias orgânicas na água subterrânea: fenóis, metanos clorados, etenos clorados, etanos clorados, benzenos clorados, hidrocarbonetos policíclicos aromáticos e hidrocarbonetos aromáticos voláteis.

\begin{tabular}{|c|c|c|c|c|c|}
\hline \multirow[b]{2}{*}{ Parâmetro } & \multirow[b]{2}{*}{ Unidade } & \multirow{2}{*}{$\begin{array}{c}\text { Poço } \\
\text { montante }\end{array}$} & \multirow{2}{*}{$\begin{array}{c}\text { Poço } \\
\text { jusante }\end{array}$} & \multicolumn{2}{|c|}{ Limite máximo } \\
\hline & & & & $\begin{array}{c}\text { CONAMA n } \\
\text { 420/2009 }\end{array}$ & $\begin{array}{l}\text { Portaria MS } \\
n^{\circ} 2914 / 2011\end{array}$ \\
\hline 1,2,3,4-Tetraclorobenzeno & $\mu \mathrm{g} . \mathrm{L}^{-1}$ & $<0,01$ & $<0,01$ & --- & --- \\
\hline 1,2,3,5-Tetraclorobenzeno & $\mu \mathrm{g} . \mathrm{L}^{-1}$ & $<0,01$ & $<0,01$ & --- & --- \\
\hline 1,2,4,5-Tetraclorobenzeno & $\mu \mathrm{g} . \mathrm{L}^{-1}$ & $<1$ & $<1$ & --- & -- \\
\hline 1,2-Diclorobenzeno & $\mu \mathrm{g} . \mathrm{L}^{-1}$ & $<1$ & $<1$ & 1000 & --- \\
\hline 1,3-Diclorobenzeno & $\mu \mathrm{g} . \mathrm{L}^{-1}$ & $<1$ & $<1$ & $\ldots$ & --- \\
\hline 1,4-Diclorobenzeno & $\mu \mathrm{g} . \mathrm{L}^{-1}$ & $<1$ & $<1$ & 300 & --- \\
\hline Triclorobenzenos & $\mu \mathrm{g} . \mathrm{L}^{-1}$ & $<3$ & $<3$ & 20 & 20 \\
\hline Hexaclorobenzeno & $\mu \mathrm{g} . \mathrm{L}^{-1}$ & $<1$ & $<1$ & 1 & --- \\
\hline Monoclorobenzeno & $\mu \mathrm{g} . \mathrm{L}^{-1}$ & $<1$ & $<1$ & 700 & 120 \\
\hline Antraceno & $\mu \mathrm{g} . \mathrm{L}^{-1}$ & $<0,05$ & $<0,05$ & --- & --- \\
\hline Benzo(a)antraceno & $\mu \mathrm{g} . \mathrm{L}^{-1}$ & $<0,05$ & $<0,05$ & 1,75 & --- \\
\hline Benzo(a)pireno & $\mu \mathrm{g} . \mathrm{L}^{-1}$ & $<0,05$ & $<0,05$ & 0,7 & 0,7 \\
\hline $\operatorname{Benzo}(g, h, i)$ perileno & $\mu \mathrm{g} . \mathrm{L}^{-1}$ & $<0,05$ & $<0,05$ & --- & --- \\
\hline Benzo(k)fluoranteno & $\mu \mathrm{g} . \mathrm{L}^{-1}$ & $<0,05$ & $<0,05$ & --- & --- \\
\hline Criseno & $\mu \mathrm{g} . \mathrm{L}^{-1}$ & $<0,05$ & $<0,05$ & --- & -- \\
\hline $\operatorname{Dibenzo}(\mathbf{a}, \mathbf{h})$ antraceno & $\mu \mathrm{g} . \mathrm{L}^{-1}$ & $<0,05$ & $<0,05$ & 0,18 & --- \\
\hline Fenantreno & $\mu \mathrm{g} . \mathrm{L}^{-1}$ & $<0,05$ & 0,08 & 140 & --- \\
\hline Indeno(1,2,3,cd)pireno & $\mu \mathrm{g} . \mathrm{L}^{-1}$ & $<0,05$ & $<0,05$ & 0,17 & --- \\
\hline Naftaleno & $\mu \mathrm{g} . \mathrm{L}^{-1}$ & $<0,05$ & 0,06 & 140 & -- \\
\hline Benzeno & $\mu \mathrm{g} . \mathrm{L}^{-1}$ & $<1$ & $<1$ & 5 & 5 \\
\hline Estireno & $\mu \mathrm{g} . \mathrm{L}^{-1}$ & $<1$ & $<1$ & 20 & 20 \\
\hline Etilbenzeno & $\mu \mathrm{g} . \mathrm{L}^{-1}$ & $<1$ & $<1$ & 300 & 200 \\
\hline Tolueno & $\mu \mathrm{g} . \mathrm{L}^{-1}$ & $<1$ & $<1$ & 700 & 170 \\
\hline Xilenos & $\mu \mathrm{g} . \mathrm{L}^{-1}$ & $<3$ & $<3$ & 500 & 300 \\
\hline
\end{tabular}

Nota: Os valores antecedidos pelo sinal de "menor que" $(<)$ indicam que a quantidade da substância não alcançou o limite de quantificação da amostra. --- Não se aplica. Amostras da água subterrânea coletadas nos poços de monitoramento no semestre 5 .

Os resultados laboratoriais referentes aos constituintes inorgânicos na água subterrânea seguem apresentados na Tabela 6 , juntamente com o limite máximo definido pela Resolução CONAMA no 420/2009, referente ao padrão de qualidade ambiental, e Portaria MS $n^{\circ}$ 2914/2011, referente ao padrão de potabilidade.

Todos os parâmetros analisados estão de acordo com o padrão de qualidade ambiental determinado na Resolução CONAMA $n^{\circ}$ 420/2009, assim como com o padrão de potabilidade definido pela Portaria MS $n^{\circ}$ 2914/2011.

O poço localizado a jusante da área de aplicação permite a coleta de amostras de água subterrânea sob influência da prática de aplicação de lodo, enquanto o poço localizado a montante permite que se obtenha amostras sem essa influência (branco ou testemunha). A maioria dos parâmetros referentes aos constituintes inorgânicos analisados não apresentou diferenças entre a amostra de água coletada a montante e a jusante.

Os parâmetros bário e zinco se apresentaram com valores mais altos no poço de jusante em comparação com o de montante, porém ambos se mantiveram bem abaixo dos limites máximos estabelecidos na Resolução CONAMA $\mathrm{n}^{\circ} 420 / 2009$ e Portaria MS $\mathrm{n}^{\circ}$ 2914/2011.

O bário é um metal alcalino terroso que ocorre na natureza principalmente nas formas de sulfato de bário e carbonato de bário, também sendo encontrado, em menor quantidade, nas rochas ígneas. A mobilidade do bário é maior em solos arenosos, com $\mathrm{pH}$ 
Tabela 6 - Constituintes inorgânicos na água subterrânea.

\begin{tabular}{|c|c|c|c|c|c|}
\hline \multirow[b]{2}{*}{ Parâmetro } & \multirow[b]{2}{*}{ Unidade } & \multirow[b]{2}{*}{ Poço montante } & \multirow[b]{2}{*}{ Poço jusante } & \multicolumn{2}{|c|}{ Limite máximo } \\
\hline & & & & $\begin{array}{c}\text { CONAMA n } \\
\text { 420/2009 } \\
\end{array}$ & $\begin{array}{c}\text { Portaria MS no } \\
2914 / 11 \\
\end{array}$ \\
\hline Alumínio & $\mu \mathrm{g} . \mathrm{L}^{-1}$ & 196 & 29,4 & 3.500 & 200 \\
\hline Antimônio & $\mu \mathrm{g} . \mathrm{L}^{-1}$ & $<1$ & $<1$ & 5 & 5 \\
\hline Arsênio & $\mu \mathrm{g} . \mathrm{L}^{-1}$ & $<1$ & $<1$ & 10 & 10 \\
\hline Bário & $\mu \mathrm{g} . \mathrm{L}^{-1}$ & 2,99 & 43,7 & 700 & 700 \\
\hline Boro & $\mu \mathrm{g} . \mathrm{L}^{-1}$ & $<1$ & $<1$ & 500 & --- \\
\hline Cádmio & $\mu \mathrm{g} . \mathrm{L}^{-1}$ & $<1$ & $<1$ & --- & 5 \\
\hline Chumbo & $\mu \mathrm{g} . \mathrm{L}^{-1}$ & $<1$ & $<1$ & 10 & 10 \\
\hline Cobalto & $\mu \mathrm{g} . \mathrm{L}^{-1}$ & $<1$ & $<1$ & 70 & --- \\
\hline Cobre & $\mu \mathrm{g} . \mathrm{L}^{-1}$ & $<1$ & $<1$ & 2.000 & 2.000 \\
\hline Cromo & $\mu \mathrm{g} . \mathrm{L}^{-1}$ & $<1$ & $<1$ & 50 & 50 \\
\hline Ferro & $\mu \mathrm{g} . \mathrm{L}^{-1}$ & 220,7 & 6,26 & 2.450 & 300 \\
\hline Manganês & $\mu \mathrm{g} . \mathrm{L}^{-1}$ & 6,18 & 8,67 & 400 & 100 \\
\hline Mercúrio & $\mu \mathrm{g} . \mathrm{L}^{-1}$ & $<0,1$ & $<0,1$ & 1 & 1 \\
\hline Molibdênio & $\mu \mathrm{g} . \mathrm{L}^{-1}$ & $<1$ & $<1$ & 70 & -- \\
\hline Níquel & $\mu \mathrm{g} . \mathrm{L}^{-1}$ & $<1$ & $<1$ & 20 & 70 \\
\hline Nitrato $($ como & $\mu \mathrm{g} . \mathrm{L}^{-1}$ & $<300$ & 370 & 10.000 & 10.000 \\
\hline Prata & $\mu \mathrm{g} . \mathrm{L}^{-1}$ & $<1$ & $<1$ & 50 & --- \\
\hline Selênio & $\mu \mathrm{g} . \mathrm{L}^{-1}$ & $<1$ & $<1$ & 10 & 10 \\
\hline Vanádio & $\mu \mathrm{g} . \mathrm{L}^{-1}$ & $<1$ & $<1$ & --- & --- \\
\hline Zinco & $\mu \mathrm{g} . \mathrm{L}^{-1}$ & 8,16 & 20,3 & 1.050 & 5.000 \\
\hline
\end{tabular}

Nota: Os valores antecedidos pelo sinal de "menor que" $(<)$ indicam que a quantidade da substância não alcançou o limite de quantificação da amostra. --- Não se aplica. Amostras da água subterrânea coletadas nos poços de monitoramento no semestre 5 .

baixo e pouca matéria orgânica, e menor em solos com maior concentração de sulfato e carbonato de cálcio (USEPA, 2005). Após aplicação de lodo da ETE de Barueri, Nogueira et al. (2010) verificaram aumento na concentração de bário no solo, que se manteve bem abaixo do valor de referência de qualidade da CETESB, e aumento também em cultura de milho (sem exceder nível o crítico para consumo humano). Magalhães et al. (2011) estudando o solo tratado com sulfato de bário verificaram que a condição de redução e saturação do solo pode propiciar aumento das frações mais lábeis deste componente, e sua consequente lixiviação. Não é esperado que o bário seja muito móvel no perfil do solo, uma vez que forma sais insolúveis e não forma complexos solúveis com materiais húmicos e fúlvicos. Apesar disso, alguns compostos do bário podem se tornar solúveis em condições

Diversos fatores afetam a solubilidade dos metais, inclusive os constituintes do solo, que podem favorecer reações de sorção ou ácidas e lixiviar para a água subterrânea (USEPA, 1984).

O zinco é um metal de transição, muito utilizado na fabricação de ligas resistentes à corrosão e na galvanização de produtos de ferro e aço. As principais fontes antropogênicas são mineração, produção de zinco, ferro e aço, corrosão de estruturas galvanizadas, combustão de carvão e incineração de resíduos. A concentração de zinco em água superficial é geralmente menor que $10 \mu \mathrm{g} . \mathrm{L}^{-1}$, enquanto nas águas subterrâneas está entre $10 \quad$ e $40 \quad \mu g . L^{-1}$ (CETESB, 2012).

Em solo arenoso que recebeu lodo de esgoto municipal foi verificado aumento da concentração de zinco no lixiviado com o aumento da dose de lodo, ocorrência de chuva e quantidades de aplicação, sendo maior na profundidade de $25 \mathrm{~cm}$ do que $50 \mathrm{~cm}$. precipitação, influenciando a mobilidade dos metais no perfil do solo (Egiarte et al., 2008).

Em solo calcário foi observado aumento da 
mobilidade do cobre, zinco e chumbo na profundidade $0-100 \mathrm{~cm}$ com a aplicação de 25 a 100 t.ha $^{-1}$ de lodo. O movimento descendente dos metais no solo que recebeu lodo parece estar mais relacionado à complexação dos metais com o carbono orgânico em solução e à superirrigação, mas também pode estar relacionado ao aumento da condutividade hidráulica do solo e à saturação da capacidade de sorção das partículas do solo devido à alta carga de metais adicionada via lodo (Yeganeh et al., 2010).

Apesar da possibilidade de lixiviação dos metais, não está claro se a diferença entre os resultados do poço montante e jusante quanto aos parâmetros bário e zinco foi causada devido à aplicação de lodo ou a algum outro fator, por exemplo, uso anterior da área. Isso porque (1) o nível freático da área de aplicação está entre 11 e 12 metros da superfície, o que reduz o risco de alteração da água subterrânea pelos metais aplicados em superfície; (2) a concentração média de bário e de zinco no solo (profundidade $0-20 \mathrm{~cm}$ ) das glebas receptoras é um pouco superior à da gleba testemunha, mas os valores não apresentaram diferença estatística $(\mathrm{p}=0,06 \mathrm{e}$ 0,20 respectivamente); (3) a concentração dos dois componentes no lodo que foi aplicado é reduzida (média de $131 \mathrm{mg} \cdot \mathrm{kg}^{-1}$ de bário e $140 \mathrm{mg} \cdot \mathrm{kg}^{-1}$ de zinco, Pereira \& Garcia, 2017).

\section{CONCLUSÕES}

A partir dos resultados acima apresentados, é possível concluir que:

a) Todos os parâmetros analisados na água subterrânea atendem ao padrão de qualidade determinado na Resolução CONAMA $n^{\circ}$ 420/2009 e ao padrão de potabilidade definido na Portaria MS no 2914/2011.

b) A água subterrânea amostrada a jusante da aplicação de lodo apresentou níveis mais altos de bário e zinco que a coletada a montante, porém ambos os parâmetros se mantiveram bem abaixo dos limites máximos estabelecidos na Resolução CONAMA $n^{\circ}$ 420/2009 e Portaria MS no 2914/2011. Não está claro se a diferença observada está relacionada à disposição do resíduo no solo.

c) Não foi verificado aumento das substâncias orgânicas potencialmente tóxicas na água subterrânea da área de aplicação de lodo em relação à testemunha.

d) Não foi verificada alteração dos indicadores microbiológicos da água subterrânea devido a aplicação de lodo no solo.

\section{REFERÊNCIAS}

APHA- AMERICAN PUBLIC HEALTH ASSOCIATION; AWWA- AMERICAN WATER WORKS ASSOCIATION; WEF- WATER ENVIRONMENT FEDERATION. Standard methods for the examination of water and wastewater. 22nd. Edition. Washington D.C., 2012. 1600 p.

ASIK, B.B.; AYDINALP, C.; KATKAT, A.V.; SAGBAN, F.O.T. Effect of the application of various wastewater sludges on the properties of sandy soil. Environmental Monitoring and Assessment, v. 187, n. 2, 2015.

BRASIL. Conselho Nacional do Meio Ambiente (CONAMA). Resolução n. 375, de 29 de agosto de 2006. Define critérios e procedimentos para o uso agrícola de lodos de esgoto gerados em estações de tratamento de esgoto sanitário e seus produtos derivados, e dá outras providências. Diário Oficial da União, Brasília, DF, 30 ago. 2006.

BRASIL. Conselho Nacional do Meio Ambiente (CONAMA). Resolução $n^{\circ} 420$, de 28 de dezembro de 2009. Dispõe sobre critérios e valores orientadores de qualidade do solo quanto à presença de substâncias químicas e estabelece diretrizes para o gerenciamento ambiental de áreas contaminadas por essas substâncias em decorrência de atividades antrópicas. Diário Oficial da União, Brasília, DF, 30 dez. 2009.

BRASIL. Portaria MS nº 2914, de 12 de dezembro de 2011. Dispõe sobre os procedimentos de controle e de vigilância

HARRISON, R.; XUE, D.; HENRY, C.; COLE, D.W. Longterm effects of heavy applications of biosolids on organic matter and nutrient content of a coarse-textured forest soil. da qualidade da água para consumo humano e seu padrão de potabilidade. Diário Oficial da União, Brasília, DF, 12 dez. 2011.

BRITO, A.P.F.; FUESS, L.T.; MENEGARIO, A.A.; JIMENEZ-RUEDA，J.R.; GARCIA，M.L. Viabilidade da disposição de lodo secundário da ETE de Araraquara (SP) em argissolo vermelho. Geociências, v. 32, p. 696-705, 2013.

CETESB. Ficha de informação toxicológica: Zinco. 2012. Disponível em: <http://www.cetesb.sp.gov.br/userfiles /file/laboratorios/fit/Zinco.pdf>. Acesso em: 26 jun. 2015.

DYNIA, J.F.; BOEIRA, R.C.; SOUZA, M.D. Nitrato no perfil de um latossolo vermelho distroférrico cultivado com milho sob aplicações sequenciais de lodo de esgoto. In: BETTIOL, W. \& CAMARGO, O. (Coordenadores). Lodo de esgoto: Impactos ambientais na agricultura. 1. ed. Jaguariúna: Embrapa, 2006, cap. 5, p. 79-89.

EGIARTE, G.; PINTO, M.; RUIZ-ROMERA, E.; CAMPS ARBESTAIN, M. Monitoring heavy metal concentrations in leachates from a forest soil subjected to repeated applications of sewage sludge. Environmental Pollution, v. 156, n. 3, p. 840-848, 2008

FUESS, L.T. \& GARCIA, M.L. Implications of stillage land disposal: A critical review on the impacts of fertigation. Journal of Environmental Management, v. 145, p. 210229 , 2014. Forest Ecology and Management, v. 66, p. 165-177, 1994.

LIRA, A.C.S.; GUEDES, M.C.; SCHALCH, V. Reciclagem de lodo de esgoto em plantação de eucalipto: carbono e 
nitrogênio. Engenharia Sanitária e Ambiental, Rio de Janeiro, v. 13, n. 2, p. 207-216, 2008.

MAGALHÃES, M.O.L.; AMARAL SOBRINHO, N.M.B. DO; ZONTA, E.; LIMA, L. DA S.; PAIVA, F.S.D. de. Mobilidade de bário em solo tratado com sulfato de bário sob condição de oxidação e redução. Química Nova, São Paulo, v. 34, n. 9, p. 1544-1549, 2011.

MÉNDEZ-CONTRERAS, J.M.; ATENODORO, J.; CHAMPIÓN, F.A.; VALLEJO-CANTÚ, N.A.; ALVARADO-LASSMAN, A. Inactivation of high concentration of pathogens in land-applied food industry sludge. Water SA, v. 35, n. 4, 2009.

MINGORANCE, M.D.; OLIVA, S.R.; VALDÉS, B.; GATA, F.J.P; LEIDI, E.O.; GUZMÁN, I.; PEÑA, A. Stabilized municipal sewage sludge addition to improve properties of an acid mine soil for plant growth. Journal of Soils and Sediments, v. 14, n. 4, p. 703-712, 2014.

NASCIMENTO, C.W.A.; BARROS, D.A.S.; MELO, E.E.C.; OLIVEIRA, A.B. Alterações químicas em solos e crescimento de milho e feijoeiro após aplicação de lodo de esgoto. Revista Brasileira de Ciência do Solo. v. 28, n. 2, p. 385-392, 2004

NOGUEIRA, T.A.R.; MELO, W.J. DE; FONSECA, I.M.; MARQUES, M.O.; HE, Z. Barium uptake by maize plants as affected by sewage sludge in a long-term field study. Journal of hazardous materials, p. 1148-1157. 2010.

PAIVA, A.V.; POGGIANI, F.; GONÇALVES, J.L.M.; FERRAZ, A.V. Crescimento de mudas de espécies arbóreas nativas, adubadas com diferentes doses de lodo de esgoto seco e com fertilização mineral. Scientia Forestalis, v. 37, n. 84, p.499-511, 2009.

PEREIRA, A.C.A. \& GARCIA, M.L. Efeitos da disposição de lodo de ETE de indústria alimentícia no solo: estudo de caso. Engenharia Sanitária e Ambiental, 2v. 22, n.3, p.531-538, 2017.

SAITO, M.L. O uso do lodo de esgoto na agricultura: precauções com os contaminantes orgânicos. Jaguariúna: Embrapa, 2007.

SANEPAR - Companhia de Saneamento do Paraná. Uso e manejo do lodo de esgoto na agricultura. Curitiba, 1999.

SILVA, S.M.C.P; FERNANDES, F.; SOCCOL, V.T.; MORITA, D.M. Principais contaminantes do lodo. In: ANDREOLI, C.V.; SPERLING, M. Von; FERNANDES, F. (Coordenadores) Lodo de esgotos: Tratamento e disposição final. Belo Horizonte: Departamento de Engenharia Sanitária e Ambiental - UFMG, Companhia de Saneamento do Paraná, 2001, cap. 3. p. 69-122. (Princípios do tratamento biológico de águas residuárias).

SILVA, C.A.; RANGEL, O.J.P; BETTIOL, W.; MANZATTO, C.V.; BOEIRA, R.C.; DYNIA, J.F. Dinâmica de metais pesados em latossolo adubado com lodo de esgoto e em plantas de milho. In: BETTIOL, W. e CAMARGO, O. (Coordenadores) Lodo de esgoto: Impactos ambientais na agricultura. 1. ed. Jaguariúna: Embrapa, 2006, cap. 4, p. 4577.
SILVA, P.H.M.; POGGIANI, F.; GONÇALVES, J.L.M.; STAPE, J.L.; MOREIRA, R.M. Crescimento de Eucalyptus grandis tratado com diferentes doses de lodos de esgoto úmido e seco, condicionados com polímeros. Scientia Forestalis, v. 36, n. 77, p. 79-88, 2008.

SMITH, S. Organic contaminants in sewage sludge (biosolids) and their significance for agricultural recycling. Philosophical Transactions of the Royal Society, v. 367, n. 1904, p. 4005-4041, 2009.

SOUZA, J.C. Avaliação da suscetibilidade e do potencial a erosão laminar da bacia do ribeirão Sozinha (GO). Goiás, 2010 Dissertação (Mestrado em Ciências Humanas)Universidade Federal de Goiás.

UNAL, M. \& KATKAT, A.V. The effects of food industry sludge on soil properties and growing of maize (Zea mays L.). Journal of Food Agriculture \& Environment, v. 7, n. 2, p. 435-440, 2009.

USEPA - UNITED STATES ENVIRONMENTAL PROTECTION AGENCY. Health effects assessment for barium. 1984. Diponível em: <http://nepis.epa.gov/Exe /ZyPDF.cgi/2000FDFS.PDF?Dockey=2000FDFS.PDF> Acesso em: 04 maio 2015.

USEPA - UNITED STATES ENVIRONMENTAL PROTECTION AGENCY. Method 8260C. Volatile organic compounds by gas chromatography/ mass spectrometry: Test methods for evaluating solid waste, physical/chemical methods (SW846). Washington: USEPA, 1996. Disponível em:<http://www.epa.gov/osw/hazard/testmethods/sw846/pdf/ 8260b.pdf >. Acesso em: $04 \mathrm{dez} .2014$.

USEPA - UNITED STATES ENVIRONMENTAL PROTECTION AGENCY. 625/R-92/013: Control of pathogens and vector attraction in sewage sludge. Washington: USEPA, 2003.

USEPA - UNITED STATES ENVIRONMENTAL PROTECTION AGENCY. Ecological soil screening levels for barium. Washington. EPA: 2005. Diponível em: $\langle$ http://rais.ornl.gov/documents/eco-ssl_barium.pdf〉. Acesso em: 04 maio 2015

USEPA - UNITED STATES ENVIRONMENTAL PROTECTION AGENCY. Method 8270D: Semivolatile organic compounds by gas chromatography/mass spectrometry. Test methods for evaluating solid waste, physical/chemical methods (SW846). Washington: USEPA, 2007.

YEGANEH, M.; AFYUNI, M.; KHOSHGOFTARMANESH, A.H., REZAEINEJAD, Y., SCHUIN, R. Transport of zinc, copper, and lead in a sewage sludge amended calcareous soil. Soil Use and Management, v. 26, n. 2, p. 176-182, 2010.

Manuscrito recebido em 9 de agosto de 2016 Revisado e aceito em 11 de novembro de 2016 